\title{
Student engagement and the transition from the first to second year in higher education
}

\section{Korhonen, Vesa}

Routledge - Taylor \& Francis Group

2017

Korhonen , V , Inkinen , M , Mattsson , M \& Toom , A 2017 , Student engagement and the transition from the first to second year in higher education . in $E$ Kyndt, $V$ Donche, $K$

Trigwell \& S Lindblom-Ylänne (eds), Higher Education Transitions : Theory and Research . New Perspectives on Learning and Instruction, Routledge - Taylor \& Francis Group , Abingdon, Oxon , pp. 113-134.

http://hdl.handle.net/10138/310654

cc_by

acceptedVersion

Downloaded from Helda, University of Helsinki institutional repository.

This is an electronic reprint of the original article.

This reprint may differ from the original in pagination and typographic detail.

Please cite the original version. 


\title{
Student engagement and the transition from the first to second year in higher education
}

\author{
Vesa Korhonen $^{\mathrm{a}}$, Mikko Inkinen ${ }^{\mathrm{b}}$, Markus Mattsson $^{\mathrm{b}}, \&$ Auli Toom $^{\mathrm{b}}$ \\ ${ }^{\text {a }}$ School of Education, University of Tampere, FIN-33014 University of Tampere, Finland; ${ }^{\mathrm{b}}$ Centre for Research and \\ Development of Higher Education, Faculty of Behavioural Sciences, University of Helsinki, P.O.BOX 9, FIN-00014 \\ University of Helsinki, Finland
}

\begin{abstract}
This study explores Finnish university students' engagement and transitions from the first to the second study year. Student engagement is an important perspective for evaluating the success of transitions, both from the individual's and institution's viewpoint, in the early stages of a student's studies. In this study, student engagement has been modelled as an interaction of individual and collective processes related to learning. There is surprisingly little research on the transitions from the first to second year of study and on engagement construction from the first year onwards. The target population in the study was university students from all 13 universities in Finland who started their studies in the autumn of 2012. Altogether, 1176 students responded to the Engagement Evaluation Questionnaire (EEQ) in the springs of 2013 and 2014. The results showed that the intensity of engagement decreases during the second year of study, while the importance of individual elements of engagement, especially academic skills, may increase within the second year. It is noteworthy that there are differences of engagement between professional and generalist disciplinary fields. The probability of weak engagement seems to be more common in generalist fields. Most worryingly, those in the weakly engaging group from the first year of study onwards seem to remain in the group quite permanently, and the probability of belonging to the group even increases in the second academic year.
\end{abstract}

Keywords: transition from the first to second year of study, student engagement, engagement evaluation, EEQ questionnaire

\section{Introduction}

Student engagement is both a theoretical construct and an empirical phenomenon that is useful when trying to understand the complex relationship between individual students and academic communities. It covers multiple academic, cognitive, emotional, behavioural, and socio-cultural 
perspectives from the viewpoint of the student's experience (Fredricks, Blumenfeld, \& Paris 2004; Coates 2007; Trowler 2010; Kahu 2013). According to previous research, strong student engagement is related to better learning outcomes, positive learning experiences, deep approach to learning, general satisfaction, well-being, and persistence related to studies (Zhao \& Kuh 2004; Carini, Kuh, \& Klein 2006; Scott 2008; Harper \& Quaye 2009; Trowler \& Trowler 2010; Millard, Bartholomew, Brand, \& Nygaard 2013; Kahu 2013). It is important to explore student engagement at different phases of university studies and more closely investigate the possible connections of strong engagement in the early stages of studies for students' success in studies and successful transitions during studies.

Another reason to investigate the characteristics of student engagement is related to improving the ability of universities to support students in their study transitions. It is relevant for student retention and for ensuring a meaningful learning process for the student (Leach \& Zepke 2011). Previous studies have shown that it is possible to influence the development of student engagement systematically and in a multi-layered way (e.g. Thomas 2002; Brooman \& Darwent 2013). The majority of the factors identified as contributing to students' behavioural, emotional, and cognitive engagement relate to institutional, instructional, and pedagogical practices (Baron \& Corbin 2012), which can be influenced and developed. Factors that can contribute to a student's experience of engagement include interactive, student-centred approaches to teaching; (inter)active learning (Brooman \& Darwent 2013); collaborative problem-solving; asking questions (Soria \& Stebleton 2012); positive, close relationships between teachers and students (Brooman \& Darwent 2013); constructive friction between students and their learning environments; sufficient academic challenge; and feedback to students (Kuh 2001; Umbach \& Wawrzynski 2005; Pike \& Kuh 2005; Matthews, Andrews, \& Adams 2011; Chickering \& Gamson 1987; Baron \& Corbin 2012; Soria \& Stebleton 2012; Kahu 2013). Despite the significance of engagement and its multiple benefits for students, surprisingly little is known about the construction of engagement, the engagement process itself, and the internal and external factors contributing to or preventing engagement during transitions at university (Kahu 2013; Brooman \& Darwent 2013). In view of these challenges, this study aims to outline the key dimensions of student engagement and show how student engagement develops from the first to the second year of study.

\section{Student transitions within university studies}


Transitions are usually associated with the main events in the life course, such as pathways from basic education to upper secondary, vocational, and higher education, and to the labour market after graduation (Ecclestone, Biesta, \& Hughes 2010). Transitions related to the context of higher education are usually examined either as transitions from secondary to tertiary education or as transitions to working life (Tight 2012). Increasingly, attention has also been paid to transitions within higher education and to identifying how to support smooth transitions (Johnston 2010; Nygaard et al. 2013). The purpose has often been to implement supportive structures and pedagogical practices to ensure successful transitions in the early stages of studies.

From the viewpoint of transitions within higher education, the first year at university has been shown to be the most crucial phase of studies (Heirdsfield, Walker, \& Walsh 2007; Johnston 2010; Brooman \& Darwent 2013). Previous research has demonstrated that students' selfesteem (Salmela-Aro \& Nurmi 2007), earlier experiences, goals and motives to study, and abilities to adapt to new practices, in conjunction with the atmosphere and participatory qualities of the community, all have an effect on the successful transition into and engagement with the academic community (Tinto 2003; Zhao \& Kuh 2004). In addition, differences in the disciplinary contexts have been shown to influence the variability of engagement (Brint, Cantwell, \& Hanneman 2008; Kahu 2013). The consequences of disengagement in transitions are serious, since disengagement may lead to student attrition, fatal changes in the study programme, withdrawal, and even failures in finalising studies (Heirdsfield et al. 2007). Studies related to the second year in university studies are often focused on attrition rates and reasons for not returning to university (Castro 2010).

It has been shown that engaged students may make significant progress in learning and cognitive abilities - for instance in reflective decision-making, critical thinking skills, and conceptual complexity - when advancing in studies from the first year (Pascarella \& Terenzini 2005). Generally, students seem to develop in the direction of deep learning and moving away from surface oriented and unregulated learning (Coertjents et.al 2013). There is also some evidence of an increasing surface style in learning in the course of studies (Nielsen, 2013). This might relate to the context favouring surface learning, since engagement is considered to be constructed in the interaction between the context and student (Pascarella \& Terenzini 2005). These differing findings might reflect what could be termed discipline-specific socialisation of learning (Nielsen, 2013).

\section{Student engagement within higher education}


Despite the significant amount of studies related to student engagement (e.g. Trowler 2010; Trowler \& Trowler 2010; Kahu 2013), the concept itself is still manifold, ambiguous, contested, and complex. The concept of engagement is used to describe the success of the study process, the progression of studies, and the students' motivation and commitment to their studies, and also when assessing higher education institutions' engagement practices (Kuh 2001; Kuh et al. 2006; Coates 2007; 2010; Leach \& Zepke 2011). In the literature, two broad areas of engagement are identified (Healey et al. 2014): 1) student engagement as a personal process, and 2) social practices related to university studies where students are involved and empowered. These conceptions of student engagement reflect engagement as a result of a variety of practices supporting learning, such as active learning, communality, participation, and communication with staff and peer students (Coates 2007). It also indicates the students' experience of involvement and support in their learning environments. Our starting point is to seek an alternative definition for engagement and we defined student engagement as the emerging bonds between an individual student and the closest study-related communities.

Previous theorisations of student engagement have emphasized communities as strengthening elements of engagement (e.g. Pike \& Kuh 2005; Kuh et al. 2006; Coates 2007; 2010). Thus, in our study, we have modelled student engagement as a reciprocal interaction of individual and collective processes related to learning (Korhonen, Inkinen, \& Toom 2015). Both social practices and the student's personal factors are important for engagement (Healey et al. 2014). Wenger's $(1998 ; 2010)$ theorization of the community of practice offers a useful starting point, because it defines learning from a social and community perspective. Knowing, meaning, and identity are constructed through participation in social actions. Therefore, we have defined student engagement as the emerging bonds between an individual student and the closest study-related communities. For successful student engagement, two intertwined and reciprocal processes are essential: the student's active agency (an individual process), and deepening participation in learning communities (a collaborative process) (cf. Wenger 1998; 2010). Participation in shared social practices comprises the engagement in a community's action and interaction (Lave \& Wenger, 1991; Wenger 1998). The individual process consists of the student's management of the necessary academic skills and the personal meaning of the studies, whereas the collaborative process covers advancing participation and social practices in academic teaching-learning communities (see Figure 1). Student engagement is constructed on the basis of these overlapping and simultaneous processes. The fundamental dimensions in the engagement process are the emerging sense of belonging and evolving identity. These both start to develop when the individual 
student within the community progressively realizes that who she or he is willing to become (Korhonen 2012; Korhonen et al. 2015).

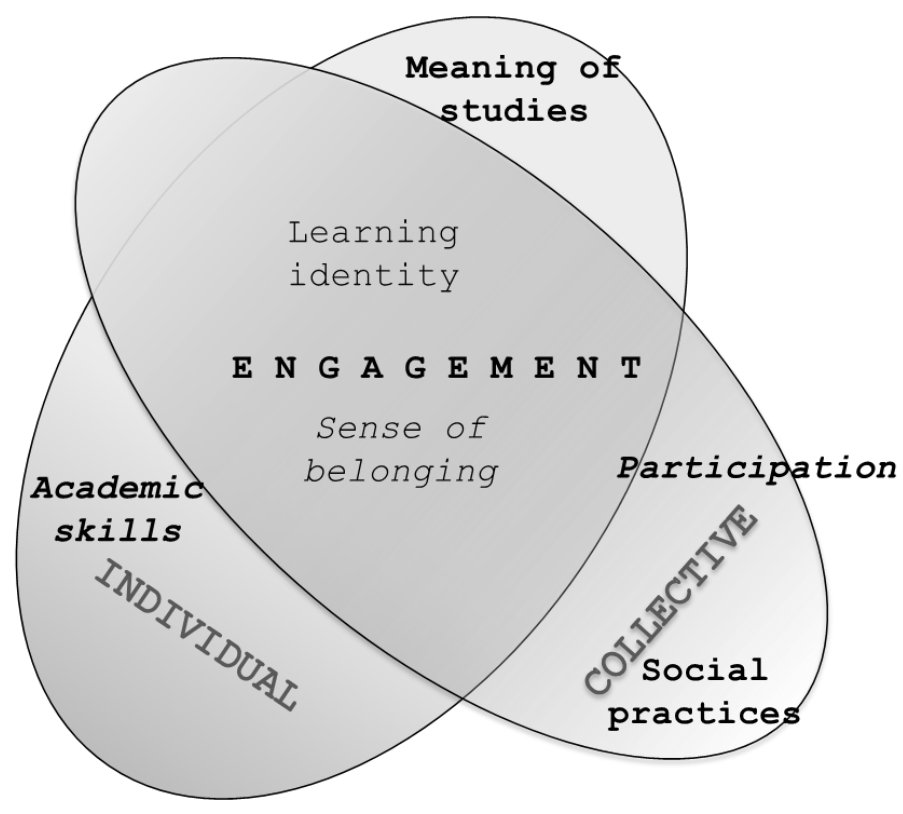

Figure 1. The main processes and elements of engagement (cf. Korhonen 2012; Korhonen, Inkinen, \& Toom 2015)

Collaborative learning in the community of practice is intertwined with four essential elements: meaning, practice, community, and identity (Wenger 1998). These elements of engagement influence each other. We have developed this understanding further by adding two elements to the engagement process and by emphasizing the viewpoint of interaction between the individual student and the academic teaching-learning communities. These two additional elements are academic skills (that individual students need for engagement) and social practices (that institutions do for engagement). These six elements altogether form the core of our engagement model that we have created and operationalized on the basis of theoretical understanding and qualitative empirical data (Korhonen 2012; Poutanen et al. 2012). In the individual process, academic skills serve as a tool for engagement (Poutanen et al. 2012). Academic skills are necessary in the beginning of higher education studies, but skills also develop as the studies progress from the first year onwards. The second element in the individual process, meaning of the studies, is a prerequisite for engagement (Poutanen et al. 2012). The personal meaning of studies may relate to the acquisition of a profession, the achievement of a higher degree, intellectual curiosity and self-development, and the creation of relations with peers. If the purpose of the studies remains unclear, this can quickly lead to drop-out or intentions to change the study field, which are 
the most common causes of a slow start and a non-committed orientation to studies (Mäkinen et al. 2004; Korhonen \& Rautopuro 2012). In the collective process, advancing participation in learning communities serves as a mediator for engagement (Poutanen et al. 2012). It entails participation and social interaction in academic communities (i.e. teaching-learning communities, the scientific community) and extra-curricular social communities (student peer communities).

The second element in the collective process, social practices in academic learning communities, promotes student engagement (Poutanen et al. 2012). Studies may include both one-way teaching situations, such as mass lectures and book exams, and guided small-group work, pair and group exams, seminars, and long-term teaching and research practice. A sense of belonging and identity develop in the engaging process, and they both have an individual and a social side. A sense of belonging deepens in the engaging process, and it is usually built into continuous encounters and shared work over a long period of time (Poutanen et al. 2012). Furthermore, the student's identity develops as a result of the engaging process (Poutanen et al. 2012). Students' identities are constructed through many positive and negative experiences in higher education. Students reflect on what kind of students they would like to be and what they are expected to be at university (Poutanen et al. 2012).

\section{Aim of the study}

The aim of this study is to investigate student engagement in higher education longitudinally, and to focus especially on the transition from the first to the second year of study within the different fields and disciplinary cultures. The six core dimensions of engagement, and their development in the transition from the first to second year, are examined. The specific research questions are:

1. How is the student engagement constructed in the transition phases of higher education?

2. How stable is student engagement individually and what kinds of changes might exist in student engagement between the first and second year of study?

3. What kinds of disciplinary differences exist in the transitions from the first to the second year of study?

\section{Methods}

\section{Participants}


The target population of the study was university students from all 13 universities in Finland who started their studies in the autumn of 2012 (16,972 students, 57\% female). From this target population, one third was randomly chosen as the sample, expect for the University of Helsinki, where all first-year students were included in the sample. Because of a small sampling error, medical students were excluded from the sample. The final sample consisted 6,040 students (65\% female, $35 \%$ male). In the spring of $2013,40 \%$ of these first-year university students $(n=2,422)$ responded the survey. At the second point of measurement in the spring of 2014, 63\% of the original participants, now representing second-year university students $(n=1,524)$, responded again the survey.

After combining the first- and the second-year data sets, altogether 1,176 students had answered all the questions used in this study in both 2013 and 2014. They were between 20 and 68 years of age (mean age 25.0 years, median age 23.0 years). In the final sample, $21.9 \%$ of the respondents were male and $78.1 \%$ were female.

\section{Measures and data collection}

Data collection was carried out as a part of the national annual survey (Finnish Student Barometer), which included background information, previous studies, study progress, first-year experiences, values, attitudes, well-being, subsistence, and employment. The national survey included our 12item engagement scale (EEQ) measuring six aspects of engagement (meaning of studies, participation, academic skills, social practices, identity, sense of belonging) (Korhonen et al. 2013; 2015). All items were measured with a seven-point Likert scale (1=strongly disagree, $7=$ strongly agree). The EEQ measurement was developed for measuring the different dimensions and characteristics of student engagement and aimed at getting an overall picture of the engagement process.

The spring was chosen for data collection because students had a sufficient experience of their study progress in both their first and second year of study, and they were better able to assess various aspects of their engagement development.

\section{Data analysis}


The aim of this study was to analyse changes in engagement between the first and second academic years. To achieve this goal, the data was analysed in two parts. Firstly, a simple descriptive statistical comparison between the first- and second-year data was carried out. Secondly, the true engagement profiles for the first- and the second-year data were investigated using latent profile analysis, and changes in engagement profiles between the first and the second year were studied with latent transition analysis.

\section{Latent profile analysis}

Latent profile analysis (LPA) is a form of mixture cluster analysis in which the distribution of the observed variables is expressed as a mixture of a finite number of unobserved (latent) variables (Masyn 2013; see also Pastor et al. 2007). In this context, the latent variables are categorical in nature, serving as indicators of cluster membership. The fact that LPA is based on a latent variable model brings about important benefits in comparison to other cluster analysis methods, such as kmeans clustering or hierarchical clustering. The fit of a model to the data can be tested, equality constraints on the values of the parameters can be placed, different models can be compared, residual statistics can be computed in order to understand sources of lack of model fit, and the same model can fit an independent sample. As a further difference to k-means and hierarchical clustering, LPA is a probabilistic clustering method, which means that each individual has a certain probability of belonging to each latent class.

LPA is also often characterized as a person-centred method to highlight the fact that the basic units of the analysis are individual persons. In using LPA as an analysis method, we assume that the student population under investigation is made up of distinct, internally homogenous subpopulations within which the observed variables have multivariate normal distributions. The subpopulations, or groups of students, are inferred based on the six subscales of the EEQ. In other words, the subscales function as indicators of the latent classes.

An important question in a latent profile analysis concerns the number of classes to extract. As noted above, this question is related to specifying the correct within-class covariance matrices. In this study, we based the decision on the number of classes on several statistical criteria, examination of residual variances and covariances, interpretability, and congruence with theory. The statistical criteria we used were those that have performed well in simulation studies (Nylund, Asparouhov, \& Muthén 2007) and examined how clearly the classes are differentiated using the 
entropy statistic (the tests are discussed from a technical perspective in Asparouhov \& Muthén 2012). The information criteria involve a penalty for model complexity, so they favour simpler models if they fit the data adequately. The logic of the two tests is to test a model with k classes against a model with k-1 classes: if the model with k classes fits significantly better, then it is to be preferred. The values of the entropy statistic range from zero to one, with higher values indicating more clearly separated classes. Further, in the context of this study, one important criterion for the number of classes (and other parameters of the model) was that the same model needed to fit the data collected for both years of the study. The exact model specifications that were used are covered in the Results section.

Due to the importance of specifying the correct within-class covariance structure, we chose to systematically compare five different types of covariance structures. When choosing among the competing structures, we used the statistical criteria outlined above (the two tests and the different information criteria). The covariance structures A-E that we tested are described in Masyn (2013). Structure A assumed local homogeneity, while in structure B, the covariances among the observed variables were freely estimated, even though they were constrained to equality across classes. Structure C differed from structure A in that the variances of the observed variables were freely estimated within the clusters. Structure D is a combination of structures B and C, while in structure E, all the variances and covariances were freely estimated within each class.

The LPA models were estimated using MPlus 7.3 (Muthén \& Muthén, 1998-2015). The default robust maximum likelihood estimator (MLR) was used. To avoid local maxima, the final models were estimated based on 1,000 initial random starting values, with 500 values with the largest log-likelihoods chosen for the second optimization step. A total of 100 iterations were performed during the first stage of the optimization. For the bootstrap-based BLRT-test, 500 bootstrap draws were performed.

Our first objective in using LPA analysis in this study was to identify student engagement profiles that would be applicable across the two years of data collection. To accomplish this, we fitted models with different numbers of classes, and with different specifications of the within-class covariance matrix. An important criterion for modifying the default covariance matrix (of equal variances across classes and zero residual covariances) was that the modifications were applicable to the data collected for both years. We examined model fit for both different numbers of clusters (from two to 8) and different within-class covariance structures. 


\section{Latent transition analysis}

Latent transition analysis (LTA) is a type of longitudinal analysis that combines cross-sectional latent class analysis (or latent profile analysis) with an autoregressive model to describe change from one latent class to another (Nylund 2007). For the applied researcher, the most interesting output from an LTA is the transition matrix, namely the conditional probabilities of being in class $\mathrm{k}$ at time $\mathrm{t}$ given that the individual was in class $\mathrm{m}$ at time $\mathrm{t}-1$. The transition probabilities are given by a multinomial logistic regression model in which dummy variables related to latent class membership at time point $\mathrm{t}-1$ act as the independent variables. In addition to predicting class membership at time $\mathrm{t}$ from class membership at time $\mathrm{t}-1$, it is possible to use other covariates as predictors. In this study, we have focused only on the former option (using category membership at time $\mathrm{t}-1$ as a predictor).

In this study, we fitted a single LTA model after choosing the optimal LPA models in the previous stage of the analysis. When fitting an LTA model, different LPA models could be used when modelling data from the different measurement occasions. In this study, however, it was possible to find a single, reasonably well-fitting model that could be used for both measurement occasions.

\section{Results}

The findings of the study make visible the engagement development between the first and second year of study transition phase in higher education. Overall, there is a slight downward trend in the level of engagement at the transition from the first to the second year of study. In the first phase of the analysis, the descriptive statistics comparison showed that student engagement was lower during the second year of studies than during the first year (Table 1). Most of the changes in means between 2013 and 2014 were statistically significant.

Table 1. The descriptive statistics for the Engagement Evaluation Questionnaire (EEQ) items and subscales in 2013 and 2014.

\begin{tabular}{|l|l|l|l|l|l|l|l|l|}
\hline & & \multicolumn{2}{|c|}{2013} & \multicolumn{2}{c|}{2014} & \multicolumn{3}{c|}{ Paired test } \\
\hline \multicolumn{1}{|c|}{ Meaning of studies (2 items) } & N & Mean & Std & Mean & Std & $\begin{array}{l}\text { Difference } \\
\text { in mean }\end{array}$ & sig 2-tail \\
\hline My current studies support my self-development. & 1176 & 5.8 & 1.1 & 5.5 & 1.1 & 0.25 & 0.00 \\
\hline I am enthusiastic about my university studies. & 1176 & 5.8 & 1.1 & 5.6 & 1.1 & 0.22 & 0.00 \\
\hline
\end{tabular}




\begin{tabular}{|l|l|l|l|l|l|l|l|}
\multicolumn{1}{|c|}{ Participation (2 items) } & 1176 & 5.6 & 1.4 & 5.4 & 1.4 & 0.18 & 0.00 \\
\hline I don't really know the other students in my subject. ${ }^{*}$ & 1176 & 6.0 & 1.5 & 5.8 & 1.5 & 0.14 & 0.00 \\
\hline I maintain contacts with other students at university. & 1176 & 5.2 & 1.5 & 4.9 & 1.6 & 0.22 & 0.00 \\
\hline \multicolumn{1}{|c|}{ Social practices (2 items) } & 1176 & 3.6 & 1.4 & 3.5 & 1.4 & 0.09 & 0.02 \\
\hline $\begin{array}{l}\text { My studies encompass a lot of work in small groups under the } \\
\text { supervision of teachers. }\end{array}$ & 1176 & 3.6 & 1.8 & 3.5 & 1.7 & 0.10 & 0.05 \\
\hline I feel that my studies are a pretty solitary enterprise. ${ }^{*}$ & 1176 & 3.5 & 1.6 & 3.4 & 1.6 & 0.08 & 0.07 \\
\hline \multicolumn{1}{|c|}{ Academic skills (2 items) } & 1176 & 4.3 & 1.4 & 4.5 & 1.4 & -0.20 & 0.00 \\
\hline I make clear timetables for my studies. & 1176 & 3.8 & 1.7 & 4.1 & 1.7 & -0.31 & 0.00 \\
\hline $\begin{array}{l}\text { I regularly do something to advance my studies, even though } \\
\text { studying may sometimes feel boring, stressful or difficult. }\end{array}$ & 1176 & 4.9 & 1.5 & 5.0 & 1.5 & -0.10 & 0.03 \\
\hline \multicolumn{1}{|c|}{ Learning identity (2 items) } & 1176 & 5.2 & 1.1 & 5.2 & 1.2 & 0.05 & 0.10 \\
\hline I fit in well as a university student. & 1176 & 5.6 & 1.2 & 5.4 & 1.3 & 0.15 & 0.00 \\
\hline $\begin{array}{l}\text { I have personally found an appropriate way to study and learn } \\
\text { at university. }\end{array}$ & 1176 & 4.9 & 1.4 & 4.9 & 1.3 & -0.05 & 0.20 \\
\hline & 1176 & 5.7 & 1.2 & 5.4 & 1.3 & 0.23 & 0.00 \\
\hline I feel like I belong to the university. & 1176 & 5.5 & 1.3 & 5.3 & 1.4 & 0.26 & 0.00 \\
\hline I feel alienated from the university. ${ }^{*}$ & 1176 & 5.8 & 1.4 & 5.6 & 1.4 & 0.20 & 0.00 \\
\hline
\end{tabular}

Many subscales of the EEQ were somewhat lower in the second year than in the first year (Table 1). The EEQ subscales of "meaning of studies", "participation", and "sense of belonging" were lower in the second year in particular, whereas "academic skills" was higher. There were only minor changes or no changes in the "social practices" and "learning identity" subscales. It seems that the individual process of engagement is slightly strengthened, while the other engagement processes (collective process together with sense of belonging and identity) decrease or remain unchanged.

\section{Latent profile analysis}

The latent profile analyses were based on different within-class covariance structure specifications (Table 2). In Table 2, the Bootstrapped Likelihood Ratio test (BLRT) results are not shown, because the test returned significant values for each and every comparison made and was thus not useful in practice.

Table 2. Fit indices and entropy values for LPA models according to each within-class covariance structure. 


\begin{tabular}{|c|c|c|c|c|c|c|c|c|c|c|}
\hline \multirow{2}{*}{$\begin{array}{l}\text { Number of clusters within } \\
\text { each covariance structure }\end{array}$} & \multicolumn{5}{|c|}{2013} & \multicolumn{5}{|c|}{2014} \\
\hline & $\mathrm{AIC}$ & $\mathrm{BIC}$ & $A B I C$ & VLMR test & Entropy & AIC & $\mathrm{BIC}$ & $A B I C$ & VLMR test & Entropy \\
\hline 2 & 27813 & 27914 & 27854 & $<0.0001$ & 0.813 & 27908 & 28009 & 27948 & $<0.0001$ & 0.828 \\
\hline 3 & 27431 & 27568 & 27486 & 0.0182 & 0.740 & 27550 & 27687 & 27605 & 0.0004 & 0.773 \\
\hline 4 & 27090 & 27265 & 27160 & 0.5012 & 0.771 & 27321 & 27495 & 27390 & 0.1935 & 0.775 \\
\hline 5 & 26921 & 27133 & 27006 & 0.0183 & 0.767 & 27163 & 27374 & 27247 & 0.2554 & 0.801 \\
\hline 6 & 26808 & 27056 & 26907 & 0.1290 & 0.781 & 27012 & 27260 & 27111 & 0.0392 & 0.782 \\
\hline 7 & 26683 & 26968 & 26797 & 0.3498 & 0.782 & 26907 & 27192 & 27020 & 0.0437 & 0.804 \\
\hline 8 & 26584 & 26907 & 26713 & 0.6191 & 0.798 & 26815 & 27137 & 26944 & 0.4638 & 0.780 \\
\hline \multicolumn{11}{|l|}{ Covariance structure B } \\
\hline 2 & 26664 & 26844 & 26736 & $<0.0001$ & 0.873 & 26759 & 26939 & 26831 & $<0.0001$ & 0.844 \\
\hline 3 & 26532 & 26748 & 26618 & $<0.0001$ & 0.843 & 26617 & 26834 & 26704 & 0.0003 & 0.861 \\
\hline 4 & 26396 & 26649 & 26497 & 0.0091 & 0.845 & 26517 & 26771 & 26618 & 0.1305 & 0.864 \\
\hline 5 & 26308 & 26599 & 26424 & 0.0723 & 0.861 & 26411 & 26702 & 26527 & 0.0033 & 0.858 \\
\hline 6 & 26231 & 26559 & 26362 & 0.2754 & 0.874 & 26357 & 26684 & 26487 & 0.0077 & 0.838 \\
\hline 7 & 26172 & 26537 & 26318 & 0.1066 & 0.881 & 26311 & 26676 & 26457 & 0.1780 & 0.845 \\
\hline 8 & 26116 & 26518 & 26276 & 0.1085 & 0.888 & 26277 & 26679 & 26438 & 0.6042 & 0.851 \\
\hline \multicolumn{11}{|l|}{ Covariance structure C } \\
\hline 2 & 27256 & 27388 & 27309 & $<0.0001$ & 0,783 & 27537 & 27670 & 27590 & $<0.0001$ & 0.770 \\
\hline 3 & 26672 & 26873 & 26752 & 0.0195 & 0.769 & 26963 & 27164 & 27043 & 0.0259 & 0.776 \\
\hline 4 & 26230 & 26500 & 26338 & 0.2942 & 0.760 & 26622 & 26892 & 26730 & 0.0279 & 0.708 \\
\hline 5 & 25990 & 26318 & 26121 & 0.0121 & 0.751 & 26433 & 26771 & 26568 & 0.2192 & 0.748 \\
\hline 6 & 25871 & 26267 & 26029 & 0.1652 & 0.754 & 26278 & 26685 & 26441 & 0.4152 & 0.745 \\
\hline 7 & 25803 & 26273 & 25990 & 0.3017 & 0.727 & 26196 & 26672 & 26386 & 0.6370 & 0.750 \\
\hline 8 & \multicolumn{5}{|c|}{ best LL not replicated } & 26129 & 26673 & 26346 & 0.3255 & 0.753 \\
\hline \multicolumn{11}{|l|}{ Covariance structure D } \\
\hline 2 & 26194 & 26405 & 26278 & $<0.0001$ & 0.671 & 26421 & 26632 & 26505 & $<0.0001$ & 0.655 \\
\hline 3 & 25945 & 26225 & 26056 & 0.0022 & 0.653 & 26227 & 26507 & 26338 & 0.0013 & 0.685 \\
\hline 4 & 25840 & 26189 & 25979 & 0.4656 & 0.670 & 26091 & 26440 & 26230 & 0.2654 & 0.712 \\
\hline 5 & 25723 & 26140 & 25889 & 0.0965 & 0.660 & 26011 & 26429 & 26178 & 0.4129 & 0.633 \\
\hline 6 & 25652 & 26138 & 25846 & 0.087 & 0.713 & 25957 & 26444 & 26151 & 0.2966 & 0.699 \\
\hline 7 & 25647 & 26203 & 25869 & 0.2115 & 0.683 & 25910 & 26465 & 26131 & 0.1506 & 0.663 \\
\hline 8 & \multicolumn{5}{|c|}{ best LL not replicated } & 25873 & 26496 & 26122 & 0.7410 & 0.683 \\
\hline \multicolumn{11}{|l|}{ Covariance structure $\mathrm{E}$} \\
\hline 2 & 26094 & 26385 & 26210 & $<0.0001$ & 0.695 & 26312 & 26602 & 26428 & $<0.0001$ & 0.642 \\
\hline 3 & 25863 & 26302 & 26038 & 0.0175 & 0.647 & 26094 & 26533 & 26269 & 0.0002 & 0.719 \\
\hline 4 & 25735 & 26322 & 25970 & 0.6553 & 0.675 & 25982 & 26568 & 26216 & 0.1686 & 0.716 \\
\hline 5 & 25651 & 26386 & 25945 & 0.1116 & 0.675 & 25919 & 26654 & 26213 & 0.3604 & 0.725 \\
\hline 6 & 25612 & 26495 & 25965 & 0.0605 & 0.713 & & best & t LL not $r$ & replicated & \\
\hline
\end{tabular}

*best LL not replicated: even with a substantial increase in the number of random starts, the best loglikelihood value was not replicated. In addition, other estimation problems (singular matrices, non-positive definite matrices) may have occurred.

The accomplished tests: The Bayesian Information Criterion (BIC), the Bootstrapped Likelihood Ratio Test (BLRT), the Adjusted Bayesian Information Criterion (ABIC), and the Vuong-Lo-Mendell-Rubin test (VLMRtest). 
The findings indicate that similar levels of model fit can be obtained by either increasing the complexity of the covariance structure or by increasing the number of latent classes (Table 2). For instance, if we use BIC as the criterion, we can see that in the data for 2014, the model with four clusters with covariance structure B fits the data roughly as well as the model with five clusters with covariance structure $\mathrm{C}$. Comparing the BIC and ABIC values of covariance structures A and B shows that the local homogeneity assumption is overly restrictive: Model B-2-2013 (covariance structure B, two clusters, 2013) fits the data better than, for instance, the model A-5-2014 (covariance structure A, five clusters, 2014). The same pattern of results is observed when looking at models built on the data from 2014. Having established that the local homogeneity assumption is overly restrictive, we can move to examining the assumption of equality of variances across clusters. Comparing covariance structures B and D, it is obvious that freeing the variances to be estimated increases model fit noticeably: as an example, the model D-2-2013 fits the data better than model B-8-2013.

The remaining question concerns the choice between the fully free covariance structure $\mathrm{E}$ and structure D. In this respect, the BIC and ABIC criteria are not in full agreement: looking at BIC, it seems that structure D should be preferred, whereas based on the sample-size adjusted ABIC criterion, structure E seems promising. Perhaps the optimal solution in this situation would be to choose structure $\mathrm{E}$, but to fine-tune the model by constraining some of the within-class covariances to zero - at least if the solution replicates on data collected on both years, or on other subsamples of the data. Such fine-tuning was, however, not carried out in the present study. Rather, with some hesitation, we chose to interpret one of the models that follow the covariance structure $\mathrm{E}$. Among these, the BIC and the VLMR-test indicate that the model with three clusters fits the data best.

Figures 2 and 3 indicate that the conditional means of the observed variables were rather similar in the three clusters across the years. The within-cluster covariances among the observed variables were also of similar magnitudes across the years. Even though no formal tests of measurement invariance were carried out, we judged the measurement models to be similar enough so that they could be used as the basis of the latent transition analysis (LTA) ${ }^{1}$.

\footnotetext{
${ }^{1}$ This is because formal tests of measurement invariance always produce a dichotomous result: either the models are invariant or they are not. Reality is likely more complex, and differences between the models come in degrees. For instance, in this case it would have been well possible that some of the within-class covariance parameters would have differed in a statistically significant, but practically non-significant manner.
} 


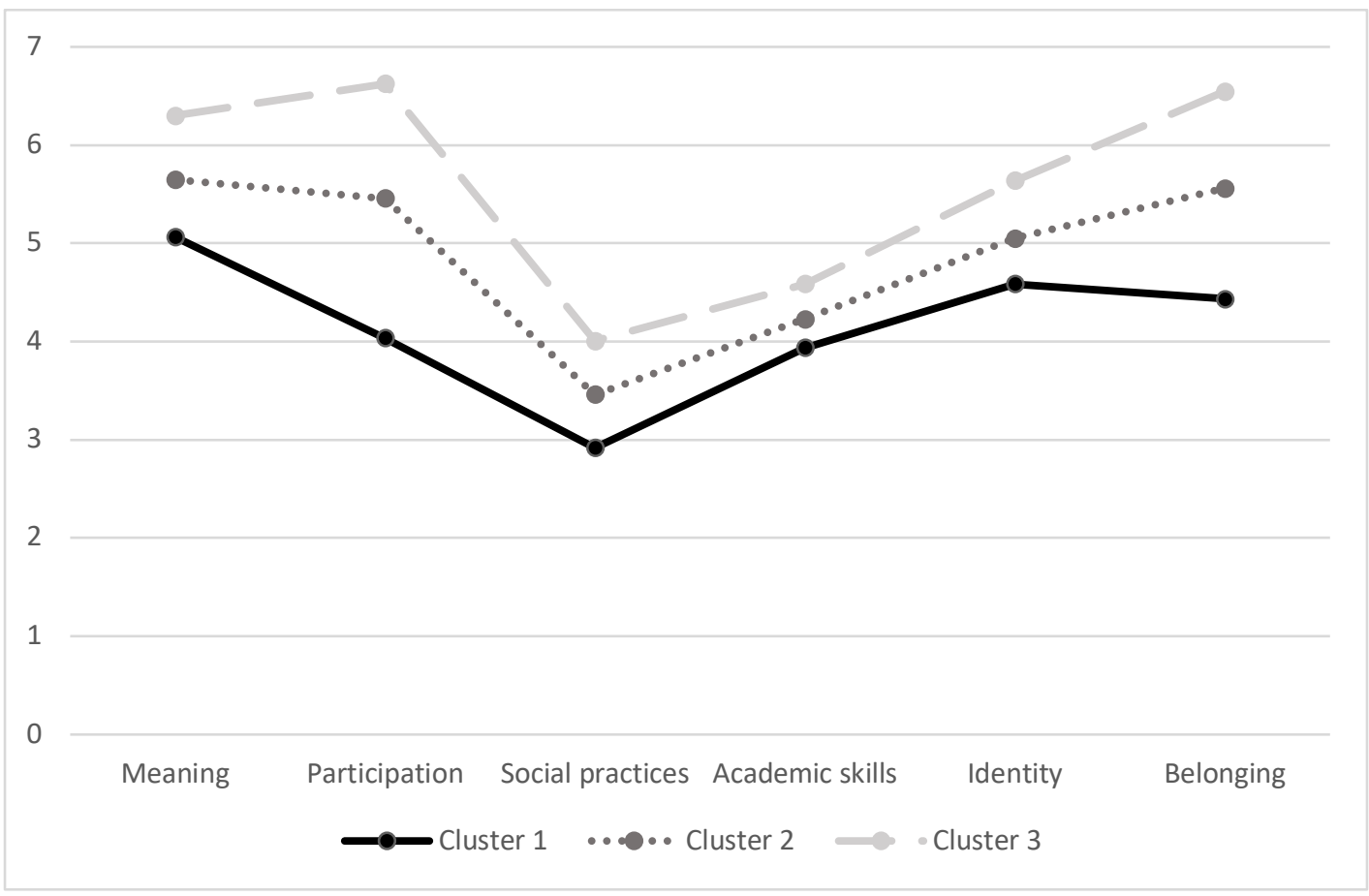

Figure 2. LPA solution for year 2013 data, covariance structure E.

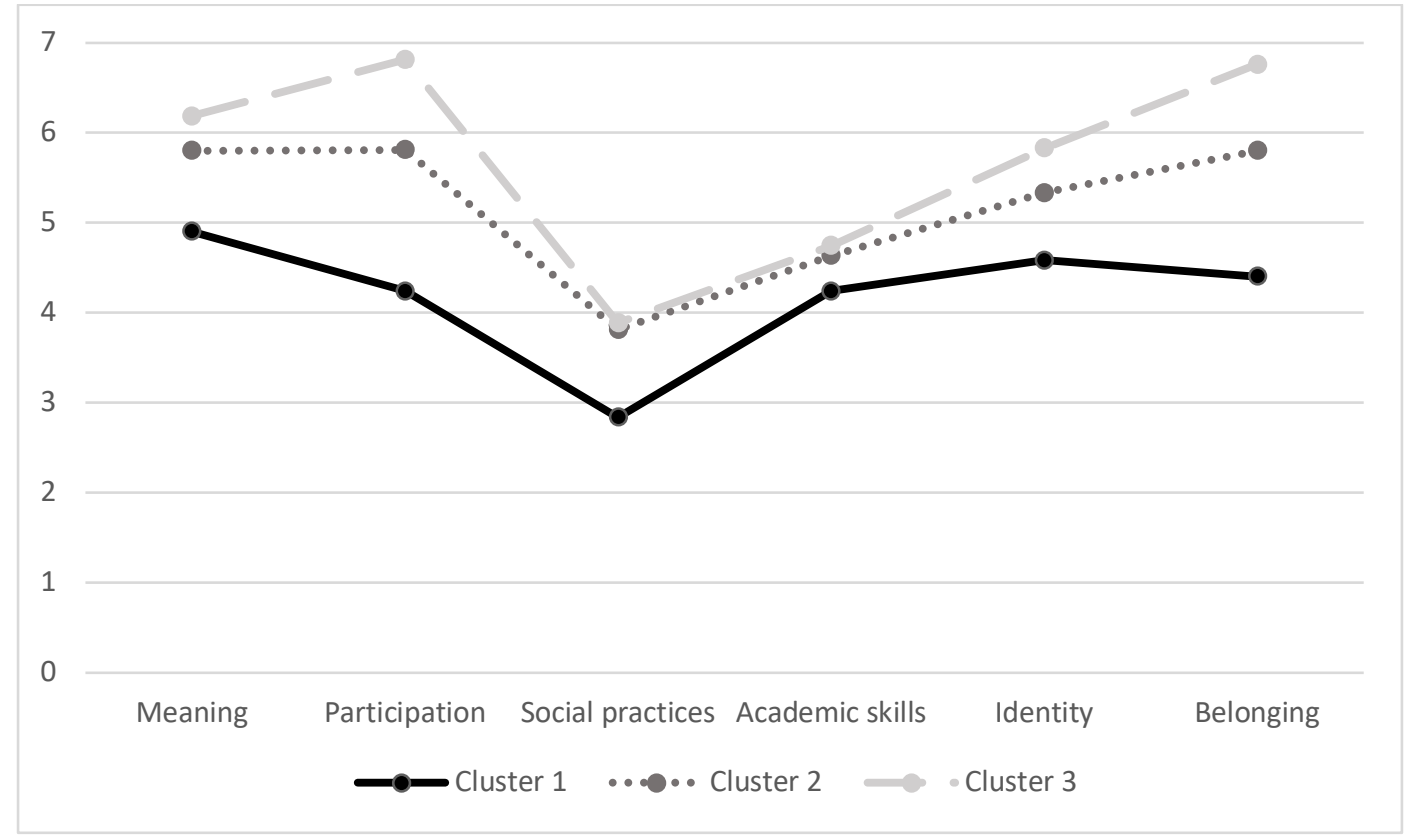

Figure 3. LPA solution for year 2014 data, covariance structure E. 
Based on an inspection of posterior probabilities, latent class 1 represented roughly $25 \%$ of students in the 2013 sample and $40 \%$ of the students in the 2014 sample. The profile plots shown in Figures 2 and 3 indicate that latent class 1 was characterized by low values in all observed variables in both samples. Class 1 was named weakly engaged. In both samples, variance among the students in latent class 1 was great, especially so in observed variables participation and academic skills. In latent class 2 , the mean values of all observed variables were slightly greater than in class 1 ; the variances on the other hand very much lower than in class 1 . The greatest variance was noted in the subscales social practices and academic skills. In the 2013 sample, latent class 2 represented roughly $43 \%$ of the students, and in 2014, roughly 46\%. Class 2 was named moderately engaged. Latent class 3, with the highest mean values in the observed values, was the most homogenous of the three classes; it had low variances in all subscales except those of social practices and academic skills. This class represented roughly $33 \%$ of students in the 2013 sample, and roughly $14 \%$ of the students in the 2014 sample. Latent class 3 was named strongly engaged.

\section{Latent transition analysis}

The three-cluster model with covariance structure $\mathrm{E}$ was chosen as the basis for the latent transition analysis. In this analysis, we specified a model in which all the freely estimated parameters were nonetheless constrained to be equal across the years: we constrained the means, variances, and within-cluster covariances of the observed variables to equality. This choice was made to ensure the comparability of the cluster structures across the years.

The results show the latent transition probabilities for the transitions between the engagement groups between the two years (Table 3). The table indicates that students who were in the first (weakly engaged) group had the highest probability of retaining their group from the first year to the second, followed by the second and third groups. Transitions from the second (moderately engaged) group were mainly towards the first group, and from the third group (strongly engaged) towards the second. Table 4 indicates the proportions of students in each combination of the groups. Figure 4 shows the estimated mean values of the observed variables in the LTA model. The means were constrained to be equal across the years; therefore only one set of lines is drawn.

Table 3. Latent transition probabilities.

2013 group 2014 group




\begin{tabular}{cccc}
\cline { 1 - 3 } & 1 & 2 & 3 \\
\hline 1 & 0.953 & 0.031 & 0.017 \\
2 & 0.130 & 0.805 & 0.064 \\
3 & 0.061 & 0.358 & 0.581 \\
\hline
\end{tabular}

Table 4. Proportions of students in each combination of the engagement groups.

\begin{tabular}{ccc}
\hline 2013 group & 2014 group & $\begin{array}{c}\text { Estimated proportion } \\
\text { of students (\%) }\end{array}$ \\
\hline 1 & 1 & 34.8 \\
1 & 2 & 1.1 \\
1 & 3 & 0.6 \\
2 & 1 & 5.2 \\
2 & 2 & 32.2 \\
2 & 3 & 2.6 \\
3 & 1 & 1.4 \\
3 & 2 & 8.4 \\
3 & 3 & 13.7 \\
\hline
\end{tabular}

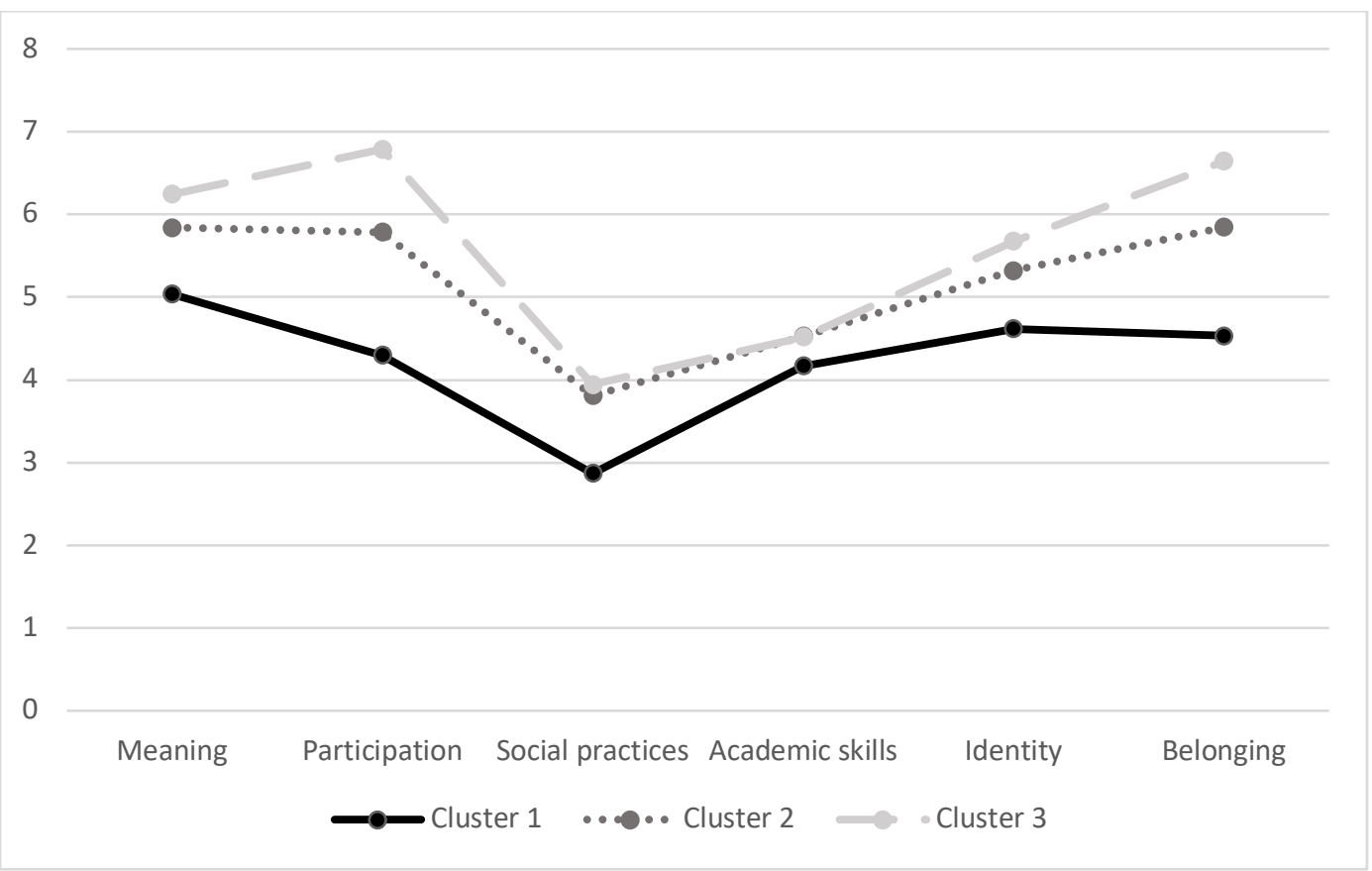

Figure 4. Estimated means in each engagement groups (cluster 1: weak; cluster 2: moderate; cluster 3: strong) of the LTA model. 
Field-specific variation between engagement groups is clear in both years (Table 5). Students in different disciplines had quite unequal probabilities of belonging to certain engagement groups. Overall, the probability of belonging to the strongly engaged group decreases significantly in every disciplinary field. Meanwhile, the probability of belonging to the weakly engaging group increases correspondingly in every disciplinary field. Therefore, a disciplinary comparison provides useful additional information on the above-mentioned engagement-level reduction between the first and second year of study.

Table 5. Probabilities of belonging to different engagement groups by discipline in the first (2013) and second (2014) academic year.

\begin{tabular}{|c|c|c|c|c|c|c|}
\hline & $\begin{array}{c}\text { Weak } \\
2013 \\
\end{array}$ & $\begin{array}{c}\text { Moderate } \\
2013 \\
\end{array}$ & $\begin{array}{c}\text { Strong } \\
2013 \\
\end{array}$ & $\begin{array}{l}\text { Weak } \\
2014 \\
\end{array}$ & $\begin{array}{c}\text { Moderate } \\
2014 \\
\end{array}$ & $\begin{array}{l}\text { Strong } \\
2014 \\
\end{array}$ \\
\hline Veterinary medicine & 0.17 & 0.36 & 0.47 & 0.26 & 0.51 & 0.23 \\
\hline Theology & 0.22 & 0.44 & 0.34 & 0.40 & 0.51 & 0.09 \\
\hline Social sciences & 0.28 & 0.49 & 0.23 & 0.51 & 0.39 & 0.11 \\
\hline Psychology & 0.17 & 0.42 & 0.41 & 0.34 & 0.49 & 0.17 \\
\hline Natural sciences & 0.32 & 0.40 & 0.28 & 0.41 & 0.43 & 0.16 \\
\hline Law & 0.14 & 0.38 & 0.49 & 0.34 & 0.36 & 0.30 \\
\hline Humanities & 0.23 & 0.49 & 0.28 & 0.44 & 0.45 & 0.11 \\
\hline Health sciences & 0.12 & 0.37 & 0.51 & 0.26 & 0.57 & 0.17 \\
\hline Pharmacology & 0.13 & 0.62 & 0.25 & 0.26 & 0.60 & 0.13 \\
\hline $\begin{array}{l}\text { Engineering and } \\
\text { technology }\end{array}$ & 0.24 & 0.35 & 0.41 & 0.38 & 0.46 & 0.16 \\
\hline Educational sciences & 0.16 & 0.40 & 0.44 & 0.28 & 0.55 & 0.18 \\
\hline $\begin{array}{l}\text { Business and } \\
\text { management }\end{array}$ & 0.19 & 0.36 & 0.45 & 0.32 & 0.56 & 0.12 \\
\hline Arts & 0.17 & 0.46 & 0.37 & 0.40 & 0.52 & 0.08 \\
\hline Agricultural sciences & 0.19 & 0.49 & 0.32 & 0.35 & 0.52 & 0.13 \\
\hline Total & 0.22 & 0.43 & 0.35 & 0.38 & 0.47 & 0.15 \\
\hline
\end{tabular}

In both 2013 and 2014, the most strongly engaged students were found in law, veterinary medicine, and the health sciences, which are all disciplines with a strong professional identity and relatively strict study programmes without many alternative study choices for students. In comparison, the most weakly engaged students were most likely to be found in the natural sciences, humanities, and social sciences, which are more generalist disciplines with relatively loose study programmes that give students a lot of choice in terms of the progress and schedule of the studies. 


\section{Discussion}

Student engagement is a crucial research topic that helps us to understand transitions within the context of higher education and within the key phases of the study path, such as in the beginning of studies (Johnston 2010). In order to follow transitions, the collection of longitudinal data over several years and from an integrative perspective is necessary (Zepke \& Leach 2010; Kahu 2013). This study aimed at finding an integrative perspective between individual and collective processes of engagement (cf. Wenger 1998; Healey et al. 2014), and stressed the importance of belonging and identity as core concepts in the engaging process. The three identified engagement groups (weak, moderate, strong) describe the differences in the intensity of the university students' first and second study year engagement process. In particular, the weakly engaged student group stood out in almost all dimensions of engagement compared to the other groups. Therefore, our results suggest that this weakly engaged group should be better recognised in university teaching, learning, and guidance arrangements. It is especially concerning that the weakly engaged group represented roughly $25 \%$ of students in the first year and $40 \%$ of the students in the second year of study. Generally noteworthy is also the modest role of social practices what institutions do for engagement, which was evaluated lowest of all dimensions in every engagement group. It seems that engaging participation is occurring mostly within student peer groups, that can be observed in participation dimension in EEQ in both years.

Interestingly, the overall picture of transitions from the first to the second year of study shows that the general level of engagement decreases towards the second year of study. The only engagement dimension that does not decrease in the respondents' evaluations - but instead increases slightly- is the subscale representing academic skills. It is natural that academic skills needed in the university context develop during studies and, in addition, this might indicate the fact that Finnish higher education requires independent and autonomous learning to a great extent. Therefore, the emphasis of the individual process in engagement is likely to increase from the first year onwards. Self-regulated and autonomous learning have been shown to be associated with academic success in many previous studies (Macaskill \& Taylor 2010; Vrugt \& Oort 2008; Brooman \& Darwent 2013). With regard to changes in engagement between the first and second year, it appears that if changes took place, it was a change downwards in engagement group (for example, from the strongly engaging group to the moderately engaging group, and so on). Most worryingly, there were hardly any changes in a positive direction for the weakest engaging group. They had the highest probability of retaining their class from the first to the second year of study. 
Based on findings of transitions from the first year onwards, our results also show that the variation of engagement in the different disciplinary fields is considerable when comparing the first and second year of study. This is probably due to the very different disciplinary teaching and learning cultures as well as the curricula regulating the progress of studies, which has been shown to shape the learners' engagement and agency (D'Andrea \& Gosling 2005; Ashwin 2008; Trowler 2008; Mathieson 2012). These field-specific differences are significant for the development of customized pedagogical practices. The difference between professional and generalist disciplinary fields is noteworthy. Support for pedagogical practices may vary depending both on the diversity of the disciplinary context and the higher education institution's general priorities (Pike \& Kuh 2005; Kuh et al. 2006). However, different disciplines might attract different types of students, who prefer different ways of learning. This might further reflect differences in student engagement. Nielsen (2013) discusses that in some fields, students especially focus on learning on the individual and detailed level (i.e. psychology), whereas in other fields they focus more on societal and abstract level (i.e. sociology). Further longitudinal studies are respectively needed concerning the variation in engagement and related contextual and discipline specific factors in the course of studies.

The EEQ instrument has only been used (and validated) among students of different fields in higher education institutes in Finland (Korhonen et al. 2013; 2015), and it has thus far not been used in higher education systems internationally. Further development of the instrument and scales is therefore necessary. The response rate in this study was satisfactory. The low representativeness of students in some fields (e.g. in medicine) is a clear weakness of the sample. Nevertheless, despite the limitations, the instrument and the longitudinal results concerning the construction of university students' engagement during the first and second year of study contribute significantly both methodologically and empirically to the literature on the student engagement.

\section{References}

Ashwin, P., 2012. Analysing Teaching-Learning Interactions in Higher Education. London: Continuum International Publishing Group.

Asparouhov, T., \& Muthén, B., 2012. Using Mplus TECH11 and TECH14 to test the number of latent classes. Mplus Web Notes, (14). Available from: http://www.statmodel.com/ [Accessed 26 November 2015].

Baron, P. and Corbin, L., 2012. Student engagement: rhetoric and reality. Higher Education Research and Development, 31 (6), 759-772. 
Brint, S., Cantwell, A. and Hanneman, R., 2008. The two cultures of undergraduate academic engagement. Research in Higher Education, 49 (5), 383-402. DOI: 10.1007/s11162-008-9090-y

Brooman, S. and Darwent, S., 2014. Measuring the beginning: a quantitative study of the transition to higher education. Studies in Higher Education, 39 (9), 1523-1541. DOI:10.1080/03075079.2013.801428

Carini, R.M., Kuh, G.D. and Klein, S.P., 2006. Student Engagement and Student Learning: Testing the Linkages. Research in Higher Education, 47 (1), 1-32. DOI: 10.1007/s11162-005-8150-9

Castro, S.M., 2010. Faculty-student interaction and advising: An exploratory analysis of non-returning second-year students at a public research university. $\mathrm{PhD}$ Thesis. Dissertation Abstracts International Section A: Humanities and Social Sciences 70 (11-A).

Chickering, A. and Gamson, Z., 1987. Seven principles for good practice in undergraduate education. AAHE Bulletin 39: 3-7.

Coates, H., 2007. A model of online and general campus-based student engagement. Assessment \& Evaluation in Higher Education, 32 (2), 121-141.

Coates, H., 2010. Development of the Australasian Survey of Student Engagement (AUSSE). Higher Education, 60 (10), 1-17.

Coertjens, L., Donche, V., De Maeyer, S., Vanthournout, G. \& Van Petegem, P. 2013. Modeling Change in Learning Strategies throughout Higher Education: A Multi-Indicator Latent Growth Perspective. PLos ONE 8 (7):e67854. doi:10.1371/journal.pone.0067854

Ecclestone, K., Biesta, G. and Hughes, M., eds., 2010.Transitions and learning through the lifecourse. London: Routledge

Fredericks, J., Blumenfeld, P. and Paris, A., 2004. School engagement: Potential of the concept, state of the evidence. Review of Educational Research, 74 (1), 59-109.

Harper, S.R. and Quaye, S.J., eds., 2009. Student Engagement in Higher Education. Theoretical Perspectives and Practical Approaches for Diverse Populations. London: Routledge.

Healey, M., Flint, A. and Harrington, K., 2014. Engagement through partnership: students as partners in learning and teaching in higher education. Pedagogic Research Report. The Higher Education Academy. Available from: https://www.heacademy.ac.uk/sites/default/files/resources/Engagement through partnership.pdf [Accessed 10 May 2015]. 
Heirdsfield, A.M., Walker, S. and Walsh, K.M., 2007. Enhancing the first year experience - Longitudinal perspectives on a peer mentoring scheme. In: Australian Association for Research in Education. Research impacts: Proving or improving, 25-29 November 2007, Fremantle, Australia. Available from: http://eprints.qut.edu.au/12150/ [Accessed 8 February 2015].

Johnston, B., 2010. The First Year at University. Teaching Students at Transition. Berkshire: The Society for Research into Higher Education \& Open University Press.

Kahu, E.R., 2013. Framing student engagement in higher education. Studies in Higher Education, 38 (5), 758-773.

Korhonen, V. 2012. Towards inclusive higher education? - Outlining a student-centered counselling framework for strengthening student engagement. In: S. Stoltz and P. Gonon, eds., Challenges and Reforms in Vocational Education - Aspects of Inclusion and Exclusion. Bern: Peter Lang, 297-320.

Korhonen, V., Inkinen, M. and Toom, A., 2013. The student engagement in examination. Evaluating Finnish first year students' engagement to their studies. In: European First Year Experience Conference at University of Helsinki, 13-15 May, 2013. Available from: http://blogs.helsinki.fi/efyehelsinki2013/files/2013/05/The-student-engagement-in-examinationEFYE2013-presentationKorhonen-Inkinen-Toom.pdf [Accessed 15 June 2015]

Korhonen, V., Inkinen, M. and Toom, A. 2015. First year students' engagement construction in Finnish higher education: engagement evaluation questionnaire and student engagement profiles. Unpublished article manuscript.

Korhonen, V. and Rautopuro, J. 2012. Miksi opinnot eivät suju? (Why studies do not progress? (Authors' transl.)) In: M. Mäkinen et al., eds., Osallistava korkeakoulutus. Tampere: Tampere University Press, 100-124.

Kuh, G.D., 2001. Assessing What Really Matters to Student Learning: Inside the National Survey of Student Engagement. Change, 33 (3), 10-17.

Kuh, G.D., Kinzie, J., Buckley, J.A., Bridges, B.K. and Hayek, J.C., 2006. What Matters to Student Success: A Review of the Literature. NPEC National Postsecondary Education Cooperative. Available from: http://nces.ed.gov/npec/pdf/kuh team_report.pdf [Accessed 21 May 2014]

Lave, J. and Wenger, E., 1991. Situated Learning: Legitimate Peripheral Participation. Cambridge: Cambridge University Press. 
Leach, L. and Zepke, N. 2011. Engaging students in learning: a review of a conceptual organizer. Higher Education Research \& Development, 30 (2), 193-204.

Masyn, K.E., 2013. Latent Class Analysis and Finite Mixture Modeling. In: P. Nathan and T. Little, eds., The Oxford Handbook of Quantitative Methods. New York, NY. Oxford University Press, 551611.

Matthews, K.E., Andrews, V. and Adams, P. 2011. Social learning spaces and student engagement. Higher Education Research \& Development, 30 (2), 105-120. DOI: 10.1080/07294360.2010.512629

Millard, L., Bartholomew, P., Brand, S. and Nygaard, C. 2013. Why Student Engagement Matters. In: C. Nygaard, et al., eds., Student Engagement - Identity, Motivation and Community. Oxfordshire: Libri Publishing, 1-16.

Muthén, L. and Muthén, B. 1998-2015. Mplus User's Guide. Version 7.3. Los Angeles, CA: Muthén \& Muthén.

Mäkinen, J., Olkinuora, E. and Lonka, K. 2004. Students at risk: Students' general study orientations and abandoning/prolonging the course of the studies. Higher Education, 48, 173-188.

Nielsen, T. 2013. Changes in BSc Business Administration and Psychology students' learning styles over one, two and three years of study. Studies in Educational Evaluation, 39 (1), 41-48.

Nygaard, C., Brand, S., Bartholomew, P. and Millard, L., eds., 2013. Student Engagement - Identity, Motivation and Community. Oxfordshire: Libri Publishing.

Nylund, K. L. 2007. Latent transition analysis: Modeling extensions and an application to peer victimization. Doctoral dissertation. University of California, Los Angeles. Available from: http://statmodel.com/ [Accessed 26 November 2015].

Nylund, K. L., Asparouhov, T. and Muthén, B. O., 2007. Deciding on the number of classes in latent class analysis and growth mixture modeling: A Monte Carlo simulation study. Structural equation modeling, 14 (4), 535-569.

Pascarella, E.T. and Terenzini, P.T. 2005. How College Affects Students. Volume 2. San Francisco, CA: Jossey-Bas.

Pastor, D. A., Barron, K. E., Miller, B. J., \& Davis, S. L. (2007). A latent profile analysis of college students' achievement goal orientation. Contemporary Educational Psychology, 32(1), 8-47. 
Pike, G.R. and Kuh, G.D. 2005. A Typology of Student Engagement for American Colleges and Universities. Research in Higher Education, 46 (2), 185-209.

Poutanen, K., Toom, A., Korhonen, V. and Inkinen, M. 2012. Kasvaako akateeminen kynnys liian korkeaksi? (Does the academic threshold grow too high? (Authors' transl.)) In: M. Mäkinen et al., eds., Osallistava korkeakoulutus. Tampere: Tampere University Press, 17-46.

Salmela-Aro, K. and Nurmi, J.-E., 2007. Self-esteem during university studies predict career 10 years later. Journal of Vocational Behavior, 70, 463-477.

Scott, G. 2008. University student engagement and satisfaction with learning and teaching. Report to the Australian Learning and Teaching Committee. Available from: http://www.uws.edu.au/ data/assets/pdf file/0007/64087/Research - Scott - pdf.pdf [Accessed 8 February 2015]

Soria, K.M. and Stebleton, M.J. 2012. First-generation students' academic engagement and retention. Teaching in Higher Education, 17(6), 673-685. DOI: 10.1080/13562517.2012.666735

Thomas, L. 2002. Student retention in higher education: The role of institutional habitus. Journal of Education Policy, 17, 423-42.

Tight, M. 2012. Researching Higher Education. 2nd Edition. Berkshire: The Society for Research into Higher Education \& Open University Press.

Tinto, V. 2003. Promoting Retention Through Classroom Practice. In: Enhancing Student Retention: Using International Policy and Practice Conference, Amsterdam, Nov. 5-7, 2003. Available from: http://www.staffs.ac.uk/access-studies/docs/Amster-paperVT(1).pdf [Accessed 25 January 2015]

Trowler, V. 2010. Student engagement literature review. The Higher Education Academy. Available from: http://www.heacademy.ac.uk/assets/documents/studentengagement/StudentEngagementLiteratureR eview.pdf [Accessed 22 May 2014]

Trowler, V. and Trowler, P. 2010. Student Engagement Evidence Summary. The Higher Education Academy. Available from: http://www.heacademy.ac.uk/assets/documents/studentengagement/StudentEngagementEvidenceS ummary.pdf [Accessed 22 May 2014]

Trowler, P. 2008. Cultures and Change in Higher Education. London: Palgrave Macmillan.

Umbach, P.D. and Wawrzynski, M.R., 2005. Faculty do matter: The role of college faculty in student learning and engagement. Research in Higher Education, 46 (2), 153-184. 
Wenger, E., 1998. Communities of Practice. Learning, Meaning, and Identity. Cambridge: Cambridge University Press.

Wenger, E. 2010. Communities of practice and social learning systems: the career of a concept. In: C. Blackmore (eds) Social Learning Systems and communities of practice. Springer Verlag and the Open University. Available from: http://wenger-trayner.com/wp-content/uploads/2012/01/09-1027-CoPs-and-systems-v2.0.pdf [Accessed 25 May 2014]

Zepke, N. and Leach, L. 2010. Beyond hard outcomes: 'soft' outcomes and engagement as student success. Teaching in Higher Education, 15 (6), 661-673.

Zhao, C. and Kuh, G.D., 2004. Adding Value: Learning Communities and Student Engagement. Research in Higher Education, 45, 115-138. 